\title{
$\int \mathbf{R}_{\text {evista }}$ Contabilidade
}

Editorial

Inicia-se o décimo ano da Revista Contemporânea de Contabilidade (RCC), publicação eletrônica quadrimestral, sob a responsabilidade do Programa de Pós-Graduação em Contabilidade e do Curso de Ciências Contábeis da Universidade Federal de Santa Catarina. O presente volume oferece 08 (oito) artigos, todos de cunho empírico.

O primeiro artigo, intitulado Práticas de gestão de custos logísticos: Estudo de caso de uma empresa do setor alimentício, de autoria de Marcos Antonio Souza, Carla Schnorr e Fernanda Baldasso Ferreira é um estudo de caso conduzido junto a uma empresa brasileira, instalada no Rio Grande do Sul que atua há mais de 20 anos na industrialização e comercialização de produtos alimentícios. O estudo investiga o uso das práticas de gestão de custos logísticos. Os resultados do estudo empírico evidenciam que: (i) apesar de os gestores da empresa não conhecerem a nomenclatura empregada pela literatura para essas práticas a empresa utiliza ferramentas que possuem o mesmo objetivo; (ii) os custos logísticos são alvos de análises estratégicas e operacionais; e, (iii) a empresa apresenta adoção de práticas de gestão em níveis superiores aos encontrados em outros estudos.

O segundo artigo, intitulado Análise das informações por segmento: divulgação de informações gerenciais pelas empresas brasileiras, é de autoria de Humberto Silva Aillón, Júlio Orestes da Silva, Anderson Ferreira Pinzan e Artur Filipe Ewald Wuerges. O artigo tem por objetivo verificar como são evidenciadas as informações gerenciais publicadas na nota explicativa de informações por segmento nas empresas que compõem o IBrX-50. A motivação dos autores para desenvolverem este trabalho vem do fato de sua obrigatoriedade de divulgação ser recente, a partir de 2010, e pode dar subsídios a diversas decisões, especialmente à análise de alocação de investimentos. Em linhas gerais os resultados evidenciaram um baixo nível de divulgação destas informações e sua evidenciação é distinta entre os diversos setores, destacando-se os setores de Mineração, Siderurgia e Metalurgia.

O terceiro artigo do presente volume, de autoria de Alex Sandro Rodrigues Martins, Alexandre Costa Quintana, Flávia Verônica Silva Jacques e Daiane Pias Machado, intitulado O balanço social como um instrumento de informação para a sociedade: um estudo na Universidade Federal do Rio Grande, elabora o Balanço Social para essa instituição pública, a partir do modelo IBASE e da adaptação às atividades específicas desta Instituição de Ensino Superior. Os resultados evidenciam a aplicabilidade deste instrumento pelas IES públicas para evidenciar informações de cunho social, ambiental, corporativo e institucional.

O quarto artigo, Quanto pior, melhor: Estudo da utilização da análise por envoltória de dados em modelos de análise de inadimplência/insolvência de empresas, é de autoria de Silvia Pereira de Castro Casa Nova. O objetivo central da pesquisa é identificar se existe vantagem na utilização da Análise por Envoltória de Dados para análise de insolvência/inadimplência em relação à Regressão Logística e Redes Neurais. O resultado 
da pesquisa apontou não haver indicação clara de superioridade de algum modelo ou procedimento.

O quinto artigo, intitulado Avaliação do sistema de controle gerencial de uma empresa do setor químico: um estudo de caso, é de autoria de Valter da Silva Faia, Joatan Bitencourt Milan e Josir Simeone Gomes. O objetivo deste estudo é analisar o sistema de controle de gestão da empresa HK Química, de pequeno porte, à luz da literatura, evidenciando os fatores predominantes de seu contexto social e organizacional que influenciaram na sua estrutura e processo de controle de gestão. Os autores observaram que o sistema de controle de gestão organizacional da HK Química diverge do referencial teórico concentrando-se somente em medidas financeiras.

O sexto artigo do presente volume, de autoria de Rafael de Lacerda Moreira, Luana Vogel Encarnação, Oscar Neto de Almeida Bispo, Marcello Angotti e Romualdo Douglas Colauto, intitulado A importância da informação contábil no processo de tomada de decisão nas micro e pequenas empresas, objetiva avaliar a percepção dos gestores do comércio varejista da cidade de Teófilo Otoni sobre a importância atribuída às informações contábeis e sua utilização nos negócios. Os resultados revelaram que os gestores não percebem a assessoria contábil como importante no auxílio às suas necessidades gerenciais, mas apenas como profissionais que fornecem serviços direcionados ao recolhimento de impostos e contribuições sociais.

O penúltimo artigo deste volume tem como título Processo de tomada de decisão e seus desdobramentos na pesquisa contábil internacional e tem Jandira Sandra Ferreira, Ricardo Lopes Cardoso e Octavio Ribeiro de Mendonça Neto como autores. O artigo propõe apresentar um panorama das pesquisas internacionais que abordam o processo de tomada de decisão em contabilidade publicadas durante o período de 1998 e 2011. Em linhas gerais, este estudo bibliométrico evidenciou o estágio incipiente desta área de pesquisa. Em decorrência deste diagnóstico constatou-se uma dispersão nos autores e nas escolas que esses autores estão vinculados.

O trabalho que fecha este volume, de autoria de Acimelly Raíza de Araújo Carneiro, Patrícia Vasconcelos Rocha Mapurunga, Vera Maria Rodrigues Ponte e Cinthya Rachel Firmino de Morais, Governança corporativa em empresas brasileiras como determinante da evidenciação de benefícios a empregados, investiga os graus de cumprimento às orientações de divulgação do CPC 33 pelas companhias listadas na BM\&FBovespa e a associação entre a observância às orientações de divulgação do CPC 33 e o segmento de listagem na BM\&FBovespa. Os autores puderam concluir que as empresas apresentaram baixo grau de atendimento às exigências do normativo e que existe uma associação positiva entre uma boa estrutura de governança (Novo Mercado) e o nível de disclosure.

A todos, uma boa leitura e até o próximo volume !

Sandra Rolim Ensslin

Editora

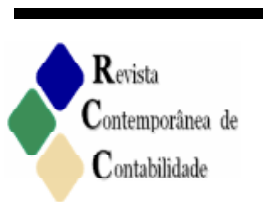

ISSN 2175-8069, UFSC, Florianópolis, v.10, n.19, p.01-02, jan./abr., 2013 